\title{
New Neotropical cunaxine species (Acari: Prostigmata: Cunaxidae)
}

\author{
JACOB DEN HEYER ${ }^{1} \&$ TATIANE MARIE MARTINS GOMES DE CASTRO ${ }^{2}$ \\ ${ }^{\prime}$ Zoology Section, Department of Entomology, Phytopathology Agricultural Zoology, Escola Superior de Agricultura "Luiz de Quei- \\ roz" (ESALQ), University of São Paulo, Piracicaba, São Paulo, Brazil, 13418-900, e-mail: jacob.den.heyer@gmail.com \\ South African address: Department of Zoology and Entomology, University of the Free State, P.O. Box 339, Bloemfontein. Website: \\ www.uovs.ac.za \\ ${ }^{2}$ Department of Plant Protection, UNESP, Campus of Jaboticabal, São Paulo, Brasil, 14884-900, e-mail: tatianemarie@yahoo.com.br
}

\begin{abstract}
Four new Brazilian cunaxine species, namely Armascirus brasiliensis Den Heyer sp. nov., A. bahiaensis Den Heyer sp. nov., Dactyloscirus saopauloensis Den Heyer sp. nov. and Riscus austroamericanus Den Heyer sp. nov. are described and figured. A key to the new species, as well as the known species of Riscus, is provided.
\end{abstract}

Key words: Bdelloidea, Armascirus, Dactyloscirus, Riscus, Neotropical fauna, keys

\section{Introduction}

Since 2006 the bdelloid fauna, especially that of the Neotropical region, has received significant systematic attention (Den Heyer \& Castro 2008 a,b,c; Castro \& Den Heyer 2008, 2009; Hernandes \& Feres 2006; Hernandes et al. 2007, 2008, 2011). Quite a number of new bdellid and cunaxid genera have been erected as a result of this work, viz. Tetrabdella, Allocunaxa, Cunaxatricha, Dunaxeus, Qunaxella and Lupaeus; and many new species have been added to these and other genera. The material studied for this paper has been collected in a wide range of geographical areas in Brazil and Peru. In this manuscript we describe four new species from the genera Armascirus, Dactyloscirus, and Riscus.

The genus Armascirus contains 38 species (Den Heyer 2011). It was erected, described, figured and historically reviewed by the senior author (Den Heyer 1978) to accommodate four southern African species as well as species such as Scirus taurus Kramer, 1881 and S. bison Berlese, 1888. Based mainly on southern African specimens he also redescribed the genus Dactyloscirus Berlese, 1916 (Den Heyer 1979b). Den Heyer (2006) erected the genus Riscus from Thailand.

\section{Materials and methods}

Mite specimens were collected by means of a Berlese funnel and mounted on slides with Hoyer's medium. Kethley's (1990) setal notation for the dorsal chaetotaxy, as adapted by Den Heyer \& Castro (2008c) for the Bdelloidea, is followed; the appendages follow that of Den Heyer (1981). The abbreviations and symbols used in this paper for the leg chaetotaxy are: asl, sharply-pointed solenidion; bsl, blunt-pointed solenidion; dtsl, dorsoterminal solenidion; fmls (= peo), famulus in depression; ms, macro seta; tsl, terminal solenidion; $\mathrm{T}$, trichobothrium; \{\}, setae between such brackets indicate duplex or triplex conditions. Setae referred to only by its notation are simple tactile setae (sts). Figures of legs represent only the distal portion of the telofemur, genua, tibiae and proximal parts of tarsi. All measurements are given in micrometers $(\mu \mathrm{m})$. Measuring bars in figures indicate $100 \mu \mathrm{m}$ unless stated otherwise; in that case the number of micrometers straddles the measuring bar.

The senior author has studied a collection of Neotropical material of the genus Armascirus and Riscus. That collection (= Neotropical cunaxine collection for this paper) consisted of about 65 specimens of the former genus 